\title{
Prostate Cancer Increases Hyaluronan in Surrounding Nonmalignant Stroma, and This Response Is Associated with Tumor Growth and an Unfavorable Outcome
}

\author{
Andreas Josefsson, ${ }^{*}$ Hani Adamo, ${ }^{*}$ \\ Peter Hammarsten, ${ }^{*}$ Torvald Granfors, ${ }^{\dagger}$ \\ Pär Stattin, ${ }^{\ddagger}$ Lars Egevad, ${ }^{\S}$ Anna Engström Laurent, ${ }^{\natural}$ \\ Pernilla Wikström, ${ }^{*}$ and Anders Bergh ${ }^{*}$ \\ From the Department of Medical Biosciences, Pathology, the \\ Department of Surgical and Perioperative Sciences, Urology and

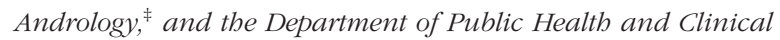 \\ Medicine, "Imeå University, Umeå; the Department of Urology, ${ }^{\dagger}$ \\ Central Hospital Västerås, Västerås; and the Department of \\ Oncology-Pathology, ${ }^{\S}$ Karolinska University Hospital, Stockholm, \\ Sweden
}

Our objective was to investigate whether the presence of a tumor increases hyaluronan (HA) levels in surrounding prostate tissues and whether this extratumoral HA influences tumor growth and outcome. From a series of 287 men diagnosed with prostate cancer at transurethral resection and followed up with watchful waiting, tissue microarrays were constructed, stained, and scored for HA. A high HA staining score in the tumor stroma or in nonmalignant prostate tissue stroma were both associated positively with higher Gleason score and larger tumor volume, and was associated with a poor outcome. HA staining score was not an independent marker for outcome (multivariate Cox, with Gleason score, tumor volume, stage, and HA variables). In an orthotopic rat prostate cancer model, hyaluronic acid synthase-1 mRNA levels and HA staining were increased in normal prostate tissue surrounding prostate cancer. Orthotopic prostate cancer growth was increased by intraprostatic injection of HA. In conclusion, cancer in the prostate apparently stimulates HA synthesis both in tumor stroma and in the surrounding normal tissue. This promoted tumor growth and was associated with an unfavorable outcome. (Am J Pathol 2011, 179:1961-1968; DOI: 10.1016/j.ajpath.2011.06.005)

Prostate cancer has a highly variable and unpredictable course. ${ }^{1-3}$ Currently, prostate cancer is diagnosed and its aggressiveness is classified by tumor stage, Gleason score, extent of tumor at biopsy, and serum levels of prostate-specific antigen (PSA). ${ }^{1}$

Recent studies have indicated that alterations in the stroma adjacent to the tumor and in more remote nonmalignant parts of the prostate also are associated with treatment response and clinical outcome. ${ }^{4}$ Prostate cancer progression is associated with loss of smooth muscle cells and an increased number of fibroblasts and myofibroblasts (cancer-associated fibroblasts) in the tumor stroma. This process, described as a reactive stroma, ${ }^{5-7}$ is similar to the stroma reaction in wounds. ${ }^{8}$ Reactive tumor stroma in prostate cancer is accompanied by changes in gene expression, ${ }^{9}$ decreased androgen-receptor staining, ${ }^{10}$ increased angiogenesis, ${ }^{11}$ accumulation of inflammatory cells, ${ }^{12-14}$ and alterations in the extracellular matrix, ${ }^{5,15}$ and the magnitude of these changes are all related to outcome.

Interestingly, the stroma in the nonmalignant parts of a prostate with cancer also is changed, indicating that the reactive stroma extends far beyond the borders of the tumor. The androgen receptor and smooth muscle markers are decreased, ${ }^{10}$ mast cells ${ }^{16}$ and platelet-derived growth factor-receptor $\beta$ are increased, ${ }^{17}$ and these alterations are related to prostate cancer death, and for androgen receptor these alterations also are related to a limited response to castration therapy. ${ }^{10}$ The mechanisms explaining why the stroma is changed in prostate cancers and in the surrounding normal prostate tissue, and why this is related to disease aggressiveness and treatment outcome, are largely unknown. Alterations in tissues surrounding tumors could be the result of carcinogenic factors influencing an entire organ, termed a cancer field effect. ${ }^{18}$ In addition, tumor epithelial cells may secrete factors that adapt the closely adjacent tumor stroma and the more remote nonmalignant prostate tissues to the needs of

Supported by grants from the Swedish Cancer Society, the Swedish Research Council (Stockholm, Sweden), and the Lions Cancer Research Foundation (Umeå, Sweden)

Accepted for publication June 28, 2011

Address reprint requests to Andreas Josefsson, M.D., Department of Medical Biosciences, Pathology, Umeå University, By 6M 2nd Floor, 901 85 Umeå, Sweden. E-mail: andreas.josefsson@medbio.umu.se. 
an expanding tumor. ${ }^{19-21}$ The surrounding tissues are in this way tinted by the presence and nature of the tumor and because such changes could be of diagnostic importance we have suggested that this tissue can be called tumorindicating normal tissue (TINT). ${ }^{10,22}$

In many tumor types hyaluronan $(\mathrm{HA})$ constitutes a major part of the extracellular matrix. ${ }^{15,23} \mathrm{HA}$ is a glucosaminoglycan (polysaccharide) important for cell division, cell migration, and angiogenesis during embryogenesis, inflammation, and wound healing. ${ }^{24,25}$ Degradation of $\mathrm{HA}$ forms a matrix that favors tumor cell invasion, epithelial to mesenchymal transition, cell proliferation, angiogenesis, lymphangiogenesis, and it recruits bone marrow-derived inflammatory and progenitor cells to tumors. ${ }^{23}$ In prostate cancer accumulation of HA in tumor stroma and altered hyaluronic acid synthase (HAS) and hyaluronidase in tumor epithelial cells, are associated with increased cell proliferation, invasion, metastasis, and poor outcome in men who have undergone radical prostatectomy. ${ }^{26-32}$ Manipulation of intratumoral HA levels in experimental animal models influences tumor growth. ${ }^{31}$

Against this background we wanted to test the hypothesis that HA levels are increased in the nonmalignant prostate tissue adjacent to prostate cancers and that the magnitude of this could be related to tumor aggressiveness.

\section{Materials and Methods}

\section{Patients}

TMAs were generated from formalin-fixed, paraffin-embedded samples from a consecutive series of 404 patients with voiding symptoms diagnosed with prostate cancer between 1975 and 1995 after transurethral resection (TUR) of the prostate (see Hammarsten et $\mathrm{al}^{22}$ for details). The TMAs contained 5 to 8 tumor cores and 4 nonmalignant tissue cores per patient. The mean age at diagnosis was 74 years (range, 53 to 95 years). Staging was performed at the time of surgery; local clinical stage was determined by digital rectal examination and radionuclide bone scan was performed for detection of metastases, but no lymph node staging was performed. Gleason score was re-assessed when the TMA was constructed. Because this series was collected before the PSA era, information on serum PSA was not available. A substantial number of our patients $(n=295)$ had not received any cancer therapy before the TUR of the prostate and were managed with watchful waiting (287 of these patients followed with watchful waiting had enough tissue in the TMAs to be evaluated). The clinicopathologic characteristics of the patients can be found in Table 1. The median overall follow-up period was 5.9 years (range, 0 to 25.5 years). The cause of death was determined by examination of patient records. Prostate cancer-specific and relative survival was very similar, indicating a correct evaluation of the cause of death. ${ }^{33}$ The Research Ethics committee in Umeå, Sweden, approved the study.

\section{Animal Experiments}

The ventral prostate lobe in adult male Copenhagen rats were injected with 2000 rat Dunning AT-1, MatLyLu prostate cancer cells, or with saline as described earlier. ${ }^{19-21}$ Animals with AT-1 tumors and controls were sacrificed after 7,10 , or 14 days ( $n=5$ to 7 , in each group) and

Table 1. Clinicopathological Characteristics and Rellation to HA Variables

\begin{tabular}{|c|c|c|c|c|}
\hline & $\begin{array}{l}\text { Analyzed cohort } \\
\qquad(n=287)\end{array}$ & $\begin{array}{c}\text { Mean HA in tumor } \\
\text { stroma }\end{array}$ & $\begin{array}{l}\text { Mean HA in tumor } \\
\text { epithelium* }\end{array}$ & $\begin{array}{l}\text { Mean HA in } \\
\text { normal stroma }\end{array}$ \\
\hline \multicolumn{5}{|l|}{ Gleason score } \\
\hline 4 to 6 & $184(64 \%)$ & $6.3( \pm 2.7)$ & $0.4( \pm 0.7)$ & $6.0( \pm 2.5)$ \\
\hline 7 & $49(17 \%)$ & $8.0( \pm 2.9)$ & $0.7( \pm 0.7)$ & $7.0( \pm 2.6)$ \\
\hline 8 to 10 & $54(19 \%)$ & $8.3( \pm 2.9)$ & $0.9( \pm 1.0)$ & $7.2( \pm 2.3)$ \\
\hline Tumor stage & & $P<0.001^{\dagger}$ & $P<0.001^{\dagger}$ & $P<0.001^{\dagger}$ \\
\hline 1 & $183(64 \%)$ & $6.7( \pm 2.8)$ & $0.5( \pm 0.7)$ & $6.4( \pm 2.6)$ \\
\hline 2 & $73(25 \%)$ & $7.0( \pm 2.7)$ & $0.5( \pm 0.8)$ & $6.5( \pm 2.5)$ \\
\hline 3 to 4 & $30(10 \%)$ & $8.9( \pm 3.5)$ & $1.2( \pm 1.1)$ & $6.5( \pm 2.3)$ \\
\hline Estimated tumor volume & & $P<0.001^{\dagger}$ & $P<0.001^{\dagger}$ & $\mathrm{NS}^{+}$ \\
\hline$<20 \%$ & $170(59 \%)$ & $6.5( \pm 2.8)$ & $0.5( \pm 0.7)$ & $6.2( \pm 2.5)$ \\
\hline$>20 \%$ & $117(41 \%)$ & $7.7( \pm 2.8)$ & $0.6( \pm 0.9)$ & $6.8( \pm 2.4)$ \\
\hline Ki-67 index in tumor areas & & $P<0.001^{\ddagger}$ & $P=0.05^{\ddagger}$ & $P<0.05^{\ddagger}$ \\
\hline$\leq 0.027$ & $165(60 \%)$ & $6.5( \pm 2.8)$ & $0.5( \pm 0.6)$ & $6.1( \pm 2.5)$ \\
\hline$>0.027$ & $108(40 \%)$ & $7.8( \pm 2.9)$ & $0.7( \pm 1.0)$ & $6.9( \pm 2.5)$ \\
\hline Vascular count in tumor & & $P<0.001^{\ddagger}$ & $\mathrm{NS}^{\ddagger}$ & $P<0.05^{f}$ \\
\hline$\leq 13.4$ & $154(57 \%)$ & $6.7( \pm 2.7)$ & $0.4( \pm 0.6)$ & $6.4( \pm 2.6)$ \\
\hline$>13.4$ & $114(43 \%)$ & $7.6( \pm 3.0)$ & $0.7( \pm 0.9)$ & $6.6( \pm 2.5)$ \\
\hline Vascular count in normal tissue & & $P<0.05^{\ddagger}$ & $\mathrm{NS}^{\ddagger}$ & $\mathrm{NS}^{\ddagger}$ \\
\hline$\leq 10.75$ & $143(52 \%)$ & $6.9( \pm 2.8)$ & $0.5( \pm 0.8)$ & $6.5( \pm 2.7)$ \\
\hline$>10.75$ & $130(48 \%)$ & $\begin{array}{c}7.3( \pm 3.0) \\
\mathrm{NS}^{\ddagger}\end{array}$ & $\begin{array}{c}0.6( \pm 0.9) \\
N^{\ddagger}\end{array}$ & $\begin{array}{c}6.4( \pm 2.3) \\
\mathrm{NS}^{\ddagger}\end{array}$ \\
\hline
\end{tabular}

The analyzed cohort of patients did not receive any treatments (followed with watchful waiting) and had no metastases at diagnosis

*The natural logarithm was used in the statistical test.

${ }^{\dagger}$ Analysis of variance was used.

₹Binary logistic regression was used.

NS, not significant $(P>0.05)$ 
animals with MatLyLu tumors and controls were sacrificed after 7 days ( $n=7$, in each group). Prostate lobes were fixed in buffered formalin or frozen in liquid nitrogen.

To examine whether injected HA affects prostate cancer growth, 2000 AT-1 cells were injected into the ventral prostate and at day 8 the ventral prostates were injected with either $400 \mu \mathrm{g} \mathrm{HA}$ in $40 \mu \mathrm{L}$ saline (Hyalgan; Nycomed, Stockholm, Sweden) or $40 \mu \mathrm{L}$ saline alone and examined 4 days later. Tumor size was determined by measuring the volume density of tumor in the ventral prostate using a stereologic approach and then multiplying the volume density by the ventral prostate lobe weight as previously described. ${ }^{19}$ All animal work was approved by the local ethical committee for animal research.

\section{HA Staining}

The TMAs and rat prostate samples were sectioned and to localize HA in the tissue sections we used a HA binding protein probe (Corgenix, Inc., Westminster, CO). The isolation and biotin labeling of the HA binding protein and the staining method used, including controls, have been described elsewhere. ${ }^{34}$ This method detects different molecular sizes of $\mathrm{HA}$.

\section{HA Scoring}

In patient samples, staining of the stroma (within tissue infiltrated by cancer and in the surrounding nonmalignant prostate tissue) was evaluated for distribution and intensity and the product of staining intensity and staining distribution was calculated (with score values between 0 and 16). Distribution was evaluated as none (0), $<10 \%(1), 10 \%$ to $50 \%$ (2), $50 \%$ to $90 \%$ (3), or more than $90 \%$ (4). Intensity was evaluated as none (0), faint (1), moderate (2), strong (3), or very strong (4). Each patient was represented by the mean value from the tumor and nonmalignant tissue cores respectively. HA staining in the epithelium was only scored by intensity. In rat samples stroma HA staining was scored for distribution (the fraction of stroma volume stained, from 0 to 1 ) and the intensity of staining (none $=0$, moderate $=1$, or strong $=2$ ). The intensity and distribution values were multiplied to obtain a HA staining score. The HA staining scores were related to previously published data of vascular density, tumor cell proliferation, estimated tumor size (percentage of the TUR chip area containing cancer), and Gleason score in this set of patients. ${ }^{35}$

\section{RNA Preparation and Quantitative RT-PCR Analysis of HAS-1 Expression}

Total RNA, from AT-1 and MatLyLu tumor tissue, intact ventral prostate tissue, normal prostate tissue adjacent to tumor, and AT-1 cells (grown in vitro), were extracted using TRIzol reagent (Invitrogen, Stockholm, Sweden) following the manufacturer's instructions. The concentration of each total RNA sample was measured with a Nanodrop ND-1000 spectrophotometer (Nanodrop Technologies, Wilmington, DE). RNA integrity was determined using the Agilent 2100 BioAnalyzer (Agilent, Wilmington,
$\mathrm{DE})$. The RNA was reverse transcribed using random hexamers (Applied Biosystems, Sundbyberg, Sweden) and Superscript II reverse transcriptase (Invitrogen). All cDNA reactions were run in duplicate. mRNA quantity was assessed by using TaqMan gene expression assays (Applied Biosystems) for HAS1 (Rn00597231_m1) and ribosomal protein S27a (Rn00821295_g1), according to the manufacturer's description. The thermal profile of the quantitative PCR was $50^{\circ} \mathrm{C}$ for 2 minutes, $95^{\circ} \mathrm{C}$ for 10 minutes, and 40 cycles of $95^{\circ} \mathrm{C}$ for 15 seconds and $60^{\circ} \mathrm{C}$ for 1 minute.

\section{Statistics}

Values are given as means and SD. Correlations between continuous variable were analyzed using the Pearson correlation test. Associations between HA variables and categoric variables (Gleason score and clinical stage) were analyzed using one-way analysis of variance and associations with the dichotomous variables were analyzed using binary logistic regression. The distribution of the values indicating HA staining was distributed normally in the tumor stroma but in the normal epithelial cells this was not the case and these values were therefore log transformed. The Mann-Whitney $U$ test was used to compare tumor weights in rats. Kaplan-Meier analysis was performed with death from prostate cancer as event, and deaths from other causes were censored and the difference in survival was tested with the log-rank test. Univariate and multiple Cox regression analysis were performed to control for other prognostic factors. Statistical analysis was performed using SPSS 17.0.0 software (SPSS, Inc., Chicago, IL). $P<0.05$ was considered statistically significant.

\section{Results}

\section{HA Staining in Malignant and Nonmalignant Human Prostate Tissues}

HA staining generally was observed in the tumor stroma and some patients also had staining in tumor epithelial cells (Figure 1). High-grade tumors had more widespread and more intense HA staining than low-grade tumors. In the surrounding nonmalignant prostate tissue HA staining was present mostly in stroma, was less common in basal cells, and was scarce in luminal epithelial cells. Basal cell staining was seen mainly in prostates containing low-grade tumors, whereas it generally was absent in cases harboring high-grade tumors. HA staining in the nonmalignant prostate tissue stroma was considerably more widespread and intense in prostates containing high-grade tumors, than in cases with low-grade variants (Table 1).

\section{HA Staining Score Is Associated with Markers of Tumor Aggressiveness}

HA staining in tumor epithelial cells and tumor stroma were correlated to Gleason score, estimated tumor volume (\% cancer in the TUR chips), tumor vascular density, and tumor 
TINT
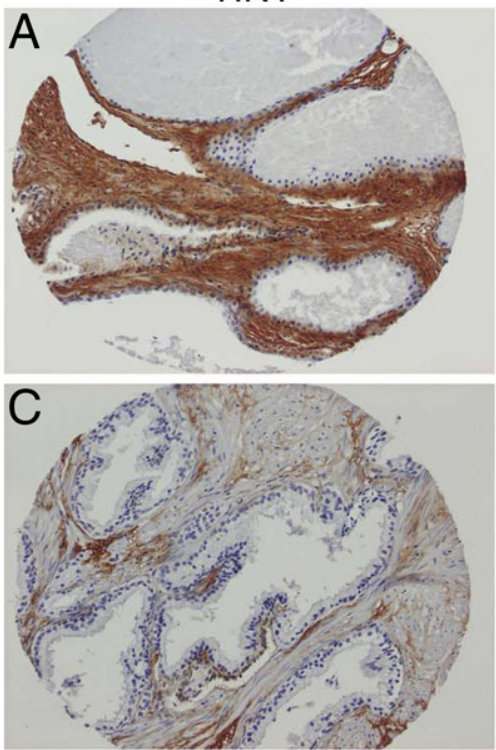

Tumor
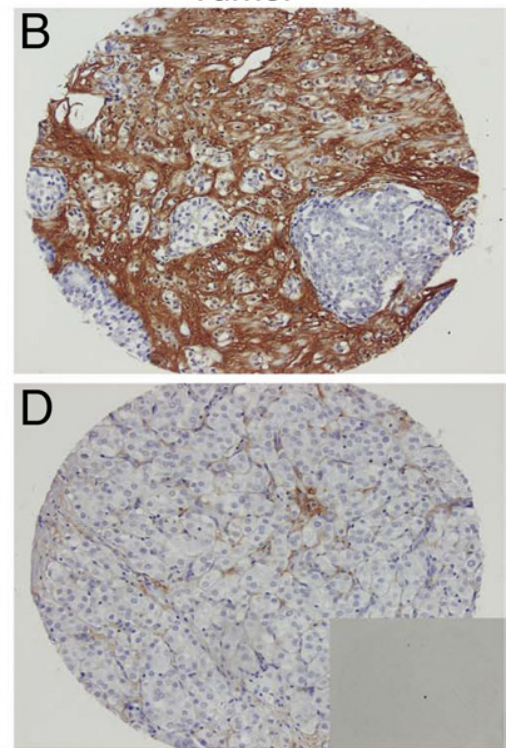

Figure 1. Tissue samples stained for HA; each tissue core is $0.6 \mathrm{~mm}$ in diameter. A: High stroma staining score in normal (TINT) tissue. B: High stroma staining score in tumor tissue. C: Low HA staining score in normal (TINT) tissue stroma (staining of the basal cells is focally present). D: Low stroma staining score in tumor stroma tissue. Inset: Lack of HA staining in a section pretreated with hyaluronidase, as described earlier in more detail. ${ }^{34}$ cell proliferation (with correlation coefficients ranging from 0.18 to 0.37; Table 1). The HA staining score in tumor epithelium and tumor stroma were correlated $(r=0.32, P<$ 0.001). To evaluate if HA staining was related to metastasis at diagnosis, the whole series of 404 men were included (treated and untreated). Patients with bone scan-detected metastasis at diagnosis $(n=46)$ had a higher HA staining score in tumor epithelium (data not shown) and tumor stroma (10.1 \pm 2.9 versus $7.2 \pm 2.9$; $P \leq 0.001)$ than patients without metastasis at diagnosis $(n=358)$.

HA staining scores in the stroma of the nonmalignant prostate tissue also was correlated with Gleason score, estimated tumor volume, and tumor cell proliferation index, but not with clinical stage or vascular density (Table 1). HA staining in the tumor stroma was correlated to $H A$ staining score in the nonmalignant prostate tissue stroma ( $r=0.33, P<0.001)$.

HA staining in basal epithelial cells in nonmalignant glands was present in $30 \%$ of the cases and was corre- lated negatively to Gleason score $(r=-0.12, P<0.05)$, local clinical stage $(r=-0.18, P<0.01)$, and estimated tumor volume $(r=-0.16, P<0.01)$.

\section{HA Staining Score in Tumor and Nonmalignant Prostate Tissue Is Associated with Prostate Cancer Death in Patients Managed by Watchful Waiting}

A HA staining score above the median in the tumor epithelium (0.4), tumor stroma (7.4), and nonmalignant prostate tissue stroma (6.25) all were associated with increased risk of prostate cancer death (Figure 2). HA staining score in stroma predicted prostate cancer death when using other possible cut-off values as the mean, and quartiles (data not shown). The presence of basal cell HA staining appeared to be associated with a lower risk of prostate cancer death, but this did not reach statistical significance $(P=0.1)$.
A

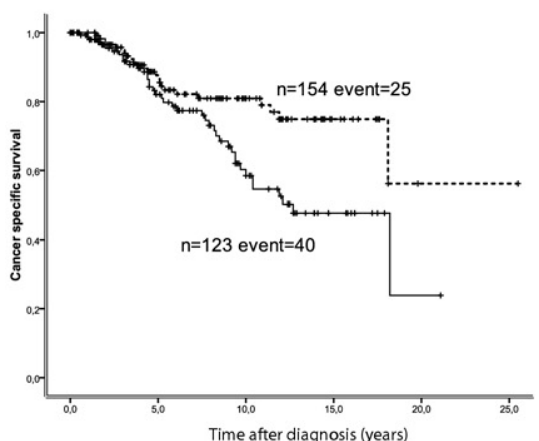

B

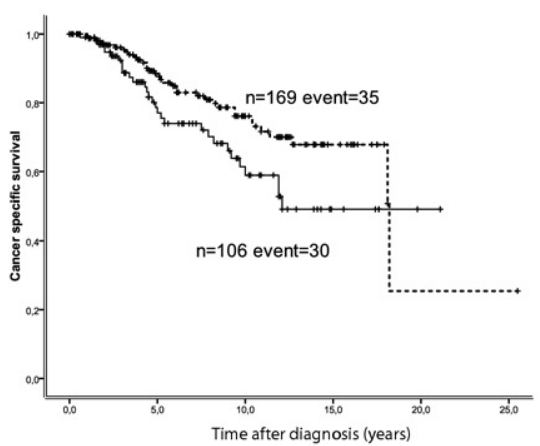

C

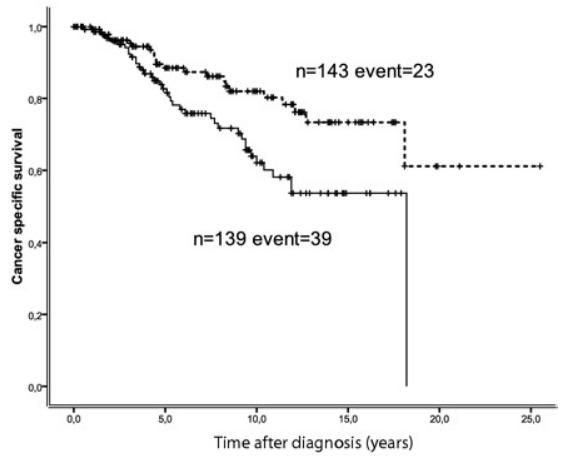

Figure 2. Kaplan-Meier curves of the analyzed cohort, divided by each variables median (solid line, above median; dashed line, under median). Patients with a Gleason score of 4 to 10 were managed with watchful waiting. Cross: Censored patients are shown. A: HA staining score in tumor stroma (log-rank test, 7.1; $P<0.01)$. B: HA staining intensity in tumor epithelium (log-rank test, $4.3 ; P<0.05)$. C: HA staining score in nonmalignant stroma $(\log -\mathrm{rank}$ test, $8.0 ; P<0.01)$. 
A

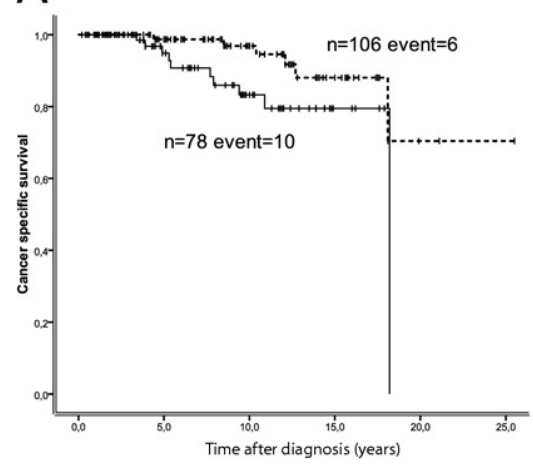

B

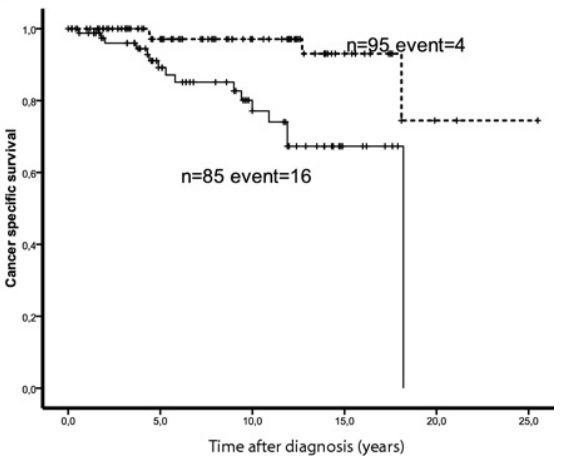

Figure 3. Kaplan-Meier curves of the analyzed subgroups of patients managed with watchful waiting divided by median of HA staining score in nonmalignant tissue (solid line, above median; dashed line, under median). A: A total of 184 patients with Gleason score of 6 or less (log-rank test, $4.7 ; P<$ 0.05). B: A total of 180 patients with clinical T1 stage, this group also included 30 patients with a Gleason score of 7 , and 13 patients with a Gleason score of 8 to 10 (log-rank rest, $13.2 ; P<0.001)$

\section{HA Staining Score Is Not an Independent Marker for Prostate Cancer Death}

In univariate Cox analysis high HA staining in tumor epithelium, tumor stroma, and nonmalignant stroma was associated with an increased risk of prostate cancer death in patients with Gleason score 4 to 10 (relative risk, 1.4; relative risk, 1.2; relative risk, 1.1 , respectively; $P<$ 0.01 ), and for the Gleason score 4 to 6 subgroup in tumor stroma (relative risk, 1.26; $P<0.05$ ). However, in multivariate analysis including estimated tumor volume, tumor stage, and Gleason score, HA staining was not an independent prognostic marker (data not shown).

\section{High HA Staining Score in Nonmalignant Prostate Tissue Is Associated with Prostate Cancer Death in Patients with Low-Grade or T1 Tumors}

In a subanalysis of the 184 patients with Gleason score 4 to 6 tumors, the HA staining score in the nonmalignant stroma was associated with prostate cancer death (Figure 3A; log-rank test, 4.7; and $P<0.05$ ). This association also was seen in the 188 patients with stage T1 tumors (log-rank test, 13.2; $P<0.001$; Figure 3B). Note, however, that the number of patients dying of prostate cancer in these groups are low and, although significant, the results therefore must be considered with some caution.

\section{HAS-1 and HA Are Increased in Growing Rat Prostate Tumors and in Surrounding Normal Tissue and HA Stimulates Tumor Growth}

Immunostaining showed strong HA staining in the rat prostate Dunning AT-1 and MatLyLu tumor stroma, but also a moderate to strong staining in the stroma of the surrounding nonmalignant prostate tissue (Figure 4). Scoring of HA staining in the nonmalignant tissue surrounding AT-1 tumors showed that it increased with tumor size from $0.33 \pm$ 0.10 at 7 days to $0.51 \pm 0.24$ at 14 days, but the difference was not statistically significant ( $P=0.12 ; n=5$ to 7$)$. The HA staining score in the nonmalignant prostate tissue surrounding the MatLyLu tumors at day $7(n=7)$ was $0.62 \pm 0.25$ and thus significantly higher $(P=0.04)$ than in prostate tissue surrounding an AT-1 tumor (Figure 4, B versus C). HAS-1 mRNA levels were higher in the nonmalignant prostate tissue surrounding AT-1 tumors than in controls (Figure 5), and, similarly, HAS-1 mRNA levels were higher in the tissue surrounding MatLyLu tumors than in controls (data not shown). Intraprostatic injection of HA stimulated the growth of AT-1 tumors. The average tumor weight (gram) was significantly higher in the HA-treated animals than in controls $(9.4 \pm 2.3$ versus $5.5 \pm 2.3 ; n=5$ to $6 ; P<0.01)$.

\section{Discussion}

The three key findings in this study were as follows: (i) an increased HA staining score in the tumor stroma was
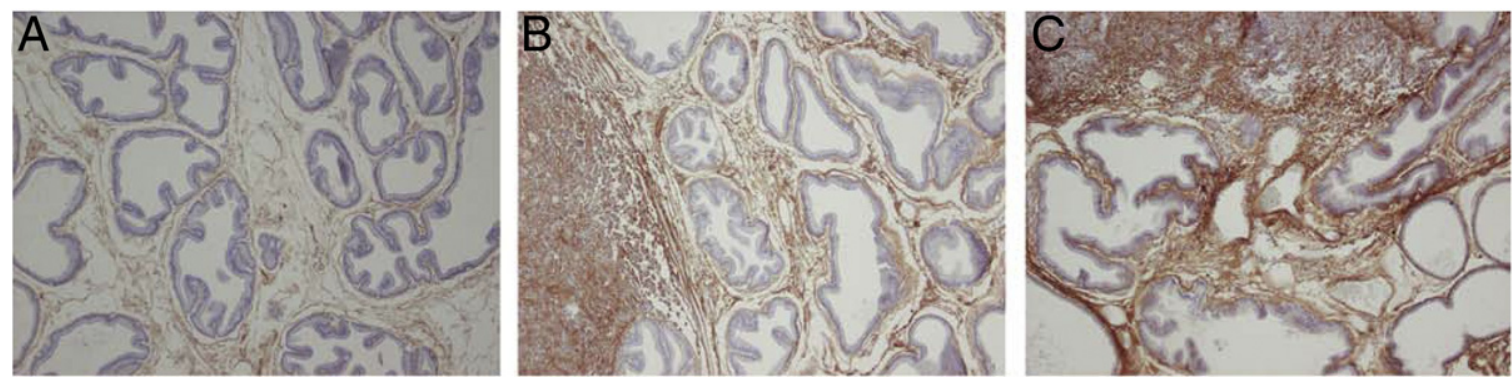

Figure 4. Photographs of rat tissues from the ventral prostate (VP), in control (A), the border zone between an AT-1 tumor (left) and adjacent VP tissue (B), and from the border zone between a MatLyLU tumor (top) and adjacent VP tissue (C) stained to visualize HA. Original magnification, $\times 200$. Note the intense staining around the MatLyLu tumor 


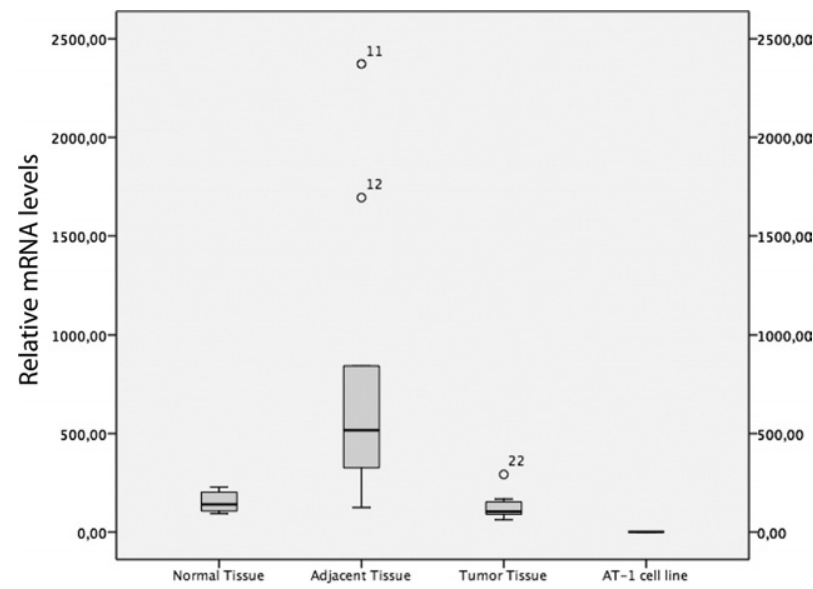

Figure 5. Box-plot showing relative HAS-1 mRNA levels in rat prostate tissues. Copenhagen rats were injected with 2000 AT-1 prostate tumor cells or saline into the ventral prostates (VPs) and examined 10 days later. The HAS- 1 expression was notably increased in VP tissue adjacent to tumor, whereas the AT-1 tumor tissue showed no difference in HAS-1 expression compared with the normal VP tissue from animals without tumors. Note that HAS-1 mRNA was not expressed in AT-1 cells in vitro.

associated with unfavorable tumor characteristics and an increased risk of prostate cancer death, (ii) exogenous administration of HA stimulated tumor growth in an animal model, and (iii) the presence of a tumor increased the HA staining score in the surrounding morphologically normal prostate tissue and the magnitude of this was associated with tumor aggressiveness and the risk of prostate cancer death. The first observation confirms previous studies but the other two are novel.

A high HA staining score in the stroma of prostate cancers was associated with high tumor cell proliferation, high vascular density, high Gleason score, high stage, and increased risk of prostate cancer death. HA, however, is, because of its correlation with Gleason score, not an independent prognosticator of prostate cancer death, although it could, if verified in other cohorts, be of some use to identify low-grade cancer that have excellent prognosis also without active treatment. It should be noted, however, that our TUR-diagnosed prostate cancers could differ from current PSA-detected tumors and studies in more contemporary cohorts are needed to evaluate the role of $\mathrm{HA}$ as a prognostic marker. Our observations on $\mathrm{HA}$ in tumor stroma in a TUR-diagnosed watchful waiting cohort are in line with previous findings in contemporary cohorts including PSA-detected tumors in men receiving active treatments, and $\mathrm{HA}$ is predictive of PSA recurrence after radical prostatectomy when evaluated in preoperative biopsies. ${ }^{26-30,32,36}$ These observations suggest that there are no apparent differences in tumor HA between biopsy- and TUR-diagnosed prostate cancer.

Receptors for HA are present on epithelial cells (CD44, CD168, and Toll-like receptors 2 and 4) and on lymph vessels in the prostate [lymphatic vessel endothelial hyaluronan receptor 1 (LYVE-1)] and these are related to tumor aggressiveness. ${ }^{26,32,37-40}$ Different moleculare HA sizes (polysacharide lengths) have different biological functions. ${ }^{24}$ Hyaluronidase degrades HA into angiogenic fragments $^{32}$ and HA directly stimulates tumor cell prolif- eration, epithelial to mesenchymal transition, and invasion. ${ }^{23,32,41}$ Together, these previous studies and the current observations clearly suggest that HA may influence prostate cancer growth by affecting several different cell types in the tumor and its surroundings. Accumulation of $\mathrm{HA}$ thus could, in addition to decreased smooth muscle markers and androgen receptor, and increased platelet-derived growth factor receptor $\beta$ (see later), be an additional marker of a tumor stroma phenotype associated with aggressive disease.

To test if injection of HA stimulated tumor growth in our orthotopic rat model we injected Hyalgan (Nycomed). This HA compound is purified from cockscomb and may, although purified, contain proteins bound to $\mathrm{HA}$, such as versican. Versican is known to act in synergy with $\mathrm{HA} .{ }^{42}$ In this experiment HA was injected when a small tumor already was formed but because HA administered simultaneously with the tumor cells also stimulated tumor growth (our own unpublished data), it is likely that HA is stimulatory at various phases of tumor establishment and growth. Further studies are needed, however, to explore in more detail how different molecular forms of HA affect tumor growth, and how HA synthesis is regulated in the tumor and in the surrounding tissue.

The mechanisms responsible for the development of a reactive stroma and increased $\mathrm{HA}$ levels in particular are largely unknown, but tumor cell secretion of tumor growth factor- $\beta$ is one likely mechanism. ${ }^{7,43}$ The expression of tumor growth factor- $\beta$ is increased in human prostate cancers $^{44}$ and in our animal model (our own unpublished observations). Tumor growth factor- $\beta$ also regulates HAS 1 to $3 .{ }^{24}$ Other growth factors produced in prostate cancers, such as insulin-like growth factor-1, fibroblast growth factor-2, and platelet-derived growth factor, also are known to stimulate HA production. ${ }^{32}$

HA has been shown to increase the recruitment of cancer-associated fibroblasts ${ }^{42}$ and macrophages, ${ }^{45}$ and they stimulate prostate cancer growth. ${ }^{12,20,21,46}$ Macrophages, which accumulate inside and around prostate tumors, in turn secrete $\mathrm{IL}-1 \beta$ and tumor necrosis factor- $\alpha,{ }^{20}$ factors known to increase HA synthesis, ${ }^{32}$ and cancer-associated fibroblasts produce HA. ${ }^{36}$ Prostate cancers are hypoxic; hypoxia makes tumors more aggressive, ${ }^{47}$ and hypoxia stimulates HA synthesis. ${ }^{48}$ Multiple mechanisms consequently may explain why HA is increased in prostate tumors and their surroundings, and why the magnitude of this is linked to disease aggressiveness. Although prostate tumors apparently increase $\mathrm{HA}$ in surrounding tissues, this is probably not the only mechanism by which prostate HA could be increased, other pathologies such as concomitant inflammation and benign prostate hyperplasia also could be involved.

One important finding in our study was that the presence of a tumor up-regulated the HA staining score, not only inside the tumor, but in the surrounding nonmalignant prostate tissue and that the magnitude of this response was associated with tumor aggressiveness and outcome in patients. HA staining in normal tissue was tightly associated with tumor characteristics and thus not a marker providing prognostic information independently of Gleason score, clinical stage, and estimated tumor 
size. To be of potential clinical use markers measured inside tumors preferably should provide information independent of tumor grade and stage, but the opposite is true for markers measured in the surrounding normal tissue (see later). Because of the lack of spatial information in TUR chips we cannot presently determine how far this response reaches into adjacent tissues (see Halin et $\mathrm{al}^{49}$ for discussion). Further studies in radical prostatectomy specimens are needed to clarify this. Similarly in rats, the HA staining score was higher in the surroundings of the metastatic MatLyLu tumor than around the nonmetastatic AT-1 variant. The reasons for this are unknown but aggressive tumors are known to secrete factors with systemic effects, for example, substances recruiting inflammatory cells and cancer-associated fibroblasts from the bone marrow and factors creating premetastatic niches in other organs. ${ }^{50}$ It is therefore not unlikely that they also could have specific effects in more adjacent tissues. In line with this, implantation of tumor cells into the rat prostate resulted in adaptive changes in the surrounding ipsilateral but also in the contralateral prostate lobe. ${ }^{19,20}$ Adaptions in the surrounding stroma, in part mediated by macrophages recruited to the tissue around tumors, ${ }^{20}$ such as growth of the supporting vasculature and tissue remodulation are probably necessary for subsequent tumor growth and metastasis. ${ }^{19-21}$ Such responses in tumor-adjacent nonmalignant tissues are morphologically similar to those seen around wounds, ${ }^{8,51}$ and the gene expression in the normal rat prostate tissue surrounding an implanted AT-1 prostate cancer is similar to that in wounding and inflammation (Adamo et al, unpublished data). Tumors apparently are able to stimulate HA synthesis, either directly or through recruiting inflammatory cells, in surrounding cells and as the tumor expands previously nonmalignant stroma becomes integrated into the tumor stroma, probably explaining why the tumor stroma and nonmalignant tissue stroma show similar changes in HA staining. Interestingly, an increased HA staining score in the nonmalignant tissue was prognostic in low-grade and low-stage disease, suggesting that aggressive tumors may have a particular effect on adjacent tissues already at an early stage of the disease.

Because the nonmalignant prostate tissue apparently senses the presence and nature of tumors elsewhere in the organ this information probably can be used for diagnostic and prognostic purposes. For example, in negative biopsies such markers potentially could indicate the risk that aggressive tumors are present elsewhere in the prostate. We have proposed that this type of prostate tissue can be termed TINT, and that prostate tissue is tinted in a particular way by the presence of aggressive tumors. ${ }^{49}$ In line with this, in TINT stroma surrounding aggressive tumors the androgen receptors are decreased, ${ }^{10}$ and mast cell numbers ${ }^{16}$ and platelet-derived growth factor-receptor $\beta$ are increased. ${ }^{17}$ In TINT epithelium surrounding aggressive tumors phosphorylated epidermal growth factor receptors and phosphorylated activated protein kinase is increased. ${ }^{22}$ Increased HA staining score apparently could be an additional TINT marker associated with prostate cancer aggressiveness as suggested in this study.

\section{Acknowledgments}

We thank Birgitta Ekblom, Elisabeth Dahlberg, Pernilla Andersson, Berith Lundström, and Sigrid Kilter for skillful technical assistance.

\section{References}

1. Andren O, Fall K, Franzen L, Andersson SO, Johansson JE, Rubin MA: How well does the Gleason score predict prostate cancer death? A 20-year followup of a population based cohort in Sweden. J Urol 2006, 175:1337-1340

2. Epstein Jl, Amin M, Boccon-Gibod L, Egevad L, Humphrey PA, Mikuz G, Newling D, Nilsson S, Sakr W, Srigley JR, Wheeler TM, Montironi R: Prognostic factors and reporting of prostate carcinoma in radical prostatectomy and pelvic lymphadenectomy specimens. Scand J Urol Nephrol Suppl 2005, 216:34-63

3. Troyer DA, Mubiru J, Leach RJ, Naylor SL: Promise and challenge: markers of prostate cancer detection, diagnosis and prognosis. Dis Markers 2004, 20:117-128

4. Bergh A: Characterization and functional role of the stroma compartment in prostate tumors. Future Oncol 2009, 5:1231-1235

5. Ayala G, Tuxhorn JA, Wheeler TM, Frolov A, Scardino PT, Ohori M, Wheeler M, Spitler J, Rowley DR: Reactive stroma as a predictor of biochemical-free recurrence in prostate cancer. Clin Cancer Res 2003, 9:4792-4801

6. Yanagisawa N, Li R, Rowley D, Liu H, Kadmon D, Miles BJ, Wheeler TM, Ayala GE: Stromogenic prostatic carcinoma pattern (carcinomas with reactive stromal grade 3 ) in needle biopsies predicts biochemical recurrence-free survival in patients after radical prostatectomy. Hum Pathol 2007, 38:1611-1620

7. Tuxhorn JA, Ayala GE, Smith MJ, Smith VC, Dang TD, Rowley DR: Reactive stroma in human prostate cancer: induction of myofibroblast phenotype and extracellular matrix remodeling. Clin Cancer Res 2002, 8:2912-2923

8. Dvorak HF: Tumors: wounds that do not heal. Similarities between tumor stroma generation and wound healing. N Engl J Med 1986, 315:1650-1659

9. Richardson AM, Woodson K, Wang Y, Rodriguez-Canales J, Erickson HS, Tangrea MA, Novakovic K, Gonzalez S, Velasco A, Kawasaki ES, Emmert-Buck MR, Chuaqui RF, Player A: Global expression analysis of prostate cancer-associated stroma and epithelia. Diagn Mol Pathol 2007, 16:189-197

10. Wikström P, Marusic J, Stattin P, Bergh A: Low stroma androgen receptor level in normal and tumor prostate tissue is related to poor outcome in prostate cancer patients. Prostate 2009, 69:799-809

11. Lissbrant IF, Lissbrant E, Damber JE, Bergh A: Blood vessels are regulators of growth, diagnostic markers and therapeutic targets in prostate cancer. Scand J Urol Nephrol 2001, 35:437-452

12. Lissbrant IF, Stattin P, Wikström P, Damber JE, Egevad L, Bergh A: Tumor associated macrophages in human prostate cancer: relation to clinicopathological variables and survival. Int J Oncol 2000, 17: 445-451

13. Karja V, Aaltomaa S, Lipponen P, Isotalo T, Talja M, Mokka R: Tumour-infiltrating lymphocytes: a prognostic factor of PSA-free survival in patients with local prostate carcinoma treated by radical prostatectomy. Anticancer Res 2005, 25:4435-4438

14. Fleischmann A, Schlomm T, Kollermann J, Sekulic N, Huland $H$, Mirlacher M, Sauter G, Simon R, Erbersdobler A: Immunological microenvironment in prostate cancer: high mast cell densities are associated with favorable tumor characteristics and good prognosis. Prostate 2009, 69:976-981

15. Tammi RH, Kultti A, Kosma VM, Pirinen R, Auvinen P, Tammi Ml: Hyaluronan in human tumors: pathobiological and prognostic messages from cell-associated and stromal hyaluronan. Semin Cancer Biol 2008, 18:288-295

16. Johansson A, Rudolfsson S, Hammarsten P, Halin S, Pietras K, Jones J, Stattin P, Egevad L, Granfors T, Wikström P, Bergh A: Mast cells are 
novel independent prognostic markers in prostate cancer and represent a target for therapy. Am J Pathol 2010, 177:1031-1041

17. Hägglof $C$, Hammarsten $P$, Josefsson A, Stattin $P$, Paulson J, Bergh A, Ostman A: Stromal PDGFR $\beta$ expression in prostate tumors and non-malignant prostate tissue predicts prostate cancer survival. PLoS One 2010, 5:e10747

18. Nonn L, Ananthanarayanan V, Gann PH: Evidence for field cancerization of the prostate. Prostate 2009, 69:1470-1479

19. Halin S, Hammarsten $P$, Wikström $P$, Bergh A: Androgen-insensitive prostate cancer cells transiently respond to castration treatment when growing in an androgen-dependent prostate environment. Prostate 2007, 67:370-377

20. Halin S, Rudolfsson SH, Van Rooijen N, Bergh A: Extratumoral macrophages promote tumor and vascular growth in an orthotopic rat prostate tumor model. Neoplasia 2009, 11:177-186

21. Halin S, Rudolfsson SH, Doll JA, Crawford SE, Wikström P, Bergh A: Pigment epithelium-derived factor stimulates tumor macrophage recruitment and is downregulated by the prostate tumor microenvironment. Neoplasia 2010, 12:336-345

22. Hammarsten $P$, Karalija $A$, Josefsson $A$, Rudolfsson $S H$, Wikström $P$, Egevad L, Granfors T, Stattin P, Bergh A: Low levels of phosphorylated epidermal growth factor receptor in nonmalignant and malignant prostate tissue predict favorable outcome in prostate cancer patients. Clin Cancer Res 2010, 16:1245-1255

23. Itano N, Kimata K: Altered hyaluronan biosynthesis in cancer progression. Semin Cancer Biol 2008, 18:268-274

24. Jiang D, Liang J, Noble PW: Hyaluronan in tissue injury and repair. Annu Rev Cell Dev Biol 2007, 23:435-461

25. Toole BP, Slomiany MG: Hyaluronan: a constitutive regulator of chemoresistance and malignancy in cancer cells. Semin Cancer Biol 2008, 18:244-250

26. Ekici S, Cerwinka WH, Duncan R, Gomez P, Civantos F, Soloway MS, Lokeshwar VB: Comparison of the prognostic potential of hyaluronic acid, hyaluronidase (HYAL-1). CD44v6 and microvessel density for prostate cancer. Int J Cancer 2004, 112:121-129

27. Lipponen P, Aaltomaa S, Tammi R, Tammi M, Agren U, Kosma VM: High stromal hyaluronan level is associated with poor differentiation and metastasis in prostate cancer. Eur J Cancer 2001, 37:849-856

28. Aaltomaa S, Lipponen P, Tammi R, Tammi M, Vittanen J, Kankkunen JP, Kosma VM: Strong stromal hyaluronan expression is associated with PSA recurrence in local prostate cancer. Urol Int 2002, 69:266-272

29. Posey JT, Soloway MS, Ekici S, Sofer M, Civantos F, Duncan RC, Lokeshwar VB: Evaluation of the prognostic potential of hyaluronic acid and hyaluronidase (HYAL1) for prostate cancer. Cancer Res 2003, 63:2638-2644

30. Gomez CS, Gomez P, Knapp J, Jorda M, Soloway MS, Lokeshwar VB: Hyaluronic acid and HYAL-1 in prostate biopsy specimens: predictors of biochemical recurrence. J Urol 2009, 182:1350-1356

31. Bharadwaj AG, Kovar JL, Loughman E, Elowsky C, Oakley GG, Simpson MA: Spontaneous metastasis of prostate cancer is promoted by excess hyaluronan synthesis and processing. Am J Pathol 2009, 174:1027-1036

32. Simpson MA, Lokeshwar VB: Hyaluronan and hyaluronidase in genitourinary tumors. Front Biosci 2008, 13:5664-5680

33. Stattin $P$, Damber JE, Karlberg L, Bergh A: Cell proliferation assessed by $\mathrm{Ki}-67$ immunoreactivity on formalin fixed tissues is a predictive factor for survival in prostate cancer. J Urol 1997, 157:219-222

34. Hellstrm M, Johansson B, Engstrm̈-Laurent A: Hyaluronan and its receptor CD44 in the heart of newborn and adult rats. Anat Rec $A$ Discov Mol Cell Evol Biol 2006, 288:587-592
35. Josefsson A, Wikström P, Granfors T, Egevad L, Karlberg L, Stattin P, Bergh A: Tumor size, vascular density and proliferation as prognostic markers in GS 6 and GS 7 prostate tumors in patients with long follow-up and non-curative treatment. Eur Urol 2005, 48:577-583

36. Lokeshwar VB, Rubinowicz D, Schroeder GL, Forgacs E, Minna JD, Block NL, Nadji M, Lokeshwar BL: Stromal and epithelial expression of tumor markers hyaluronic acid and HYAL1 hyaluronidase in prostate cancer. J Biol Chem 2001, 276:11922-11932

37. Lin SL, Chang D, Chiang A, Ying SY: Androgen receptor regulates $\mathrm{CD} 168$ expression and signaling in prostate cancer. Carcinogenesis 2008, 29:282-290

38. Dhir R, Gau JT, Krill D, Bastacky S, Bahnson RR, Cooper DL, Becich $\mathrm{MJ}$ : CD44 expression in benign and neoplastic human prostates. Mol Diagn 1997, 2:197-204

39. Trojan L, Michel MS, Rensch F, Jackson DG, Alken P, Grobholz R: Lymph and blood vessel architecture in benign and malignant prostatic tissue: lack of lymphangiogenesis in prostate carcinoma assessed with novel lymphatic marker lymphatic vessel endothelial hyaluronan receptor (LYVE-1). J Urol 2004, 172:103-107

40. Hua D, Liu MY, Cheng ZD, Qin XJ, Zhang HM, Chen Y, Qin GJ, Liang G, Li JN, Han XF, Liu DX: Small interfering RNA-directed targeting of Toll-like receptor 4 inhibits human prostate cancer cell invasion, survival, and tumorigenicity. Mol Immunol 2009, 46:2876-2884

41. Toole BP, Zoltan-Jones A, Misra S, Ghatak S: Hyaluronan: a critical component of epithelial-mesenchymal and epithelial-carcinoma transitions. Cells Tissues Organs 2005, 179:66-72

42. Itano N, Zhuo L, Kimata K: Impact of the hyaluronan-rich tumor microenvironment on cancer initiation and progression. Cancer Sci 2008, 99:1720-1725

43. Tuxhorn JA, Ayala GE, Rowley DR: Reactive stroma in prostate cancer progression. J Urol 2001, 166:2472-2483

44. Wikström P, Stattin P, Franck-Lissbrant I, Damber JE, Bergh A: Transforming growth factor beta1 is associated with angiogenesis, metastasis, and poor clinical outcome in prostate cancer. Prostate 1998 37:19-29

45. Kuang DM, Wu Y, Chen N, Cheng J, Zhuang SM, Zheng L: Tumorderived hyaluronan induces formation of immunosuppressive macrophages through transient early activation of monocytes. Blood 2007, 110:587-595

46. Koyama H, Kobayashi N, Harada M, Takeoka M, Kawai Y, Sano K, Fujimori M, Amano J, Ohhashi T, Kannagi R, Kimata K, Taniguchi S, Itano N: Significance of tumor-associated stroma in promotion of intratumoral lymphangiogenesis: pivotal role of a hyaluronan-rich tumor microenvironment. Am J Pathol 2008, 172:179-193

47. Rudolfsson SH, Bergh A: Hypoxia drives prostate tumour progression and impairs the effectiveness of therapy, but can also promote cell death and serve as a therapeutic target. Expert Opin Ther Targets 2009, 13:219-225

48. Gao F, Okunieff P, Han Z, Ding I, Wang L, Liu W, Zhang J, Yang S, Chen J, Underhill CB, Kim S, Zhang L: Hypoxia-induced alterations in hyaluronan and hyaluronidase. Adv Exp Med Biol 2005, 566:249-256

49. Halin S, Hammarsten $\mathrm{P}$, Adamo H, Wikström P, Bergh A: Tumour indicating normal tissue (TINT) could be a novel source of diagnostic and prognostic markers for prostate cancer. Exp Opin Med Diagn 2011, 5:37-47

50. McAllister SS, Weinberg RA: Tumor-host interactions: a far-reaching relationship. J Clin Oncol 2010, 28:4022-4028

51. Orimo A, Weinberg RA: Stromal fibroblasts in cancer: a novel tumorpromoting cell type. Cell Cycle 2006, 5:1597-1601 